\title{
Falling off the Ladder: using Focal Theory to understand and improve the educational experiences of young people in transition from public care
}

\section{Abstract}

Coleman's focal theory, developed in relation to adolescents in the general population, appears to offer some explanation for the poor educational achievement and social exclusion of care leavers, but has been little tested empirically. This paper revisits data from two studies of care-experienced young people aged $18-25$, drawing on qualitative interviews in the UK and four other European countries, to see if focal theory would have helped to predict their educational progression or otherwise. The lives of research participants were found to be characterised by disruptions and uncertainty, with multiple challenges confronting them in quick succession, making it hard for them to pace their transitions as, according to focal theory, other young people do. Findings suggest that the theory could be used to inform policy designed to improve educational outcomes and should be incorporated into training for those responsible for supporting care leavers through their transition to adulthood.

Keywords: Leaving care; Focal theory; Transition to adulthood; Education; 


\section{Falling off the Ladder: using Focal Theory to understand and improve the educational experiences of young people in transition from public care}

\section{Introduction}

Why do care leavers, removed from abusive and neglectful homes to supposedly more nurturing and supportive placements, run such a high risk of social exclusion in adulthood? One reason, confirmed by extensive research, is that the vast majority leave care with no educational qualifications (Jackson, 2007). This is one of the most consistent findings from studies of care leavers in many different countries (Stein \& Munro, 2008). Over the past 20 years UK governments have introduced numerous policy initiatives designed to raise the educational attainment of young people in and leaving care and thereby improve their life chances, but with only modest success (Cameron, Connelly \& Jackson 2015). There has been little theoretical discussion of the reasons for the generally poor outcomes for care leavers. Indeed, Mike Stein has referred to 'the poverty of theory' in this field (Stein, 2006) and proposed Coleman's 'focal theory' as shedding light on the problems of young people moving to independence.

\section{Focal Theory and the transition to adulthood from care}

Focal theory was developed by Coleman $(1974 ; 1978 ; 1989)$ as a framework for understanding psychosocial transitions in middle and late adolescence and grew out of a large scale study of 'normative' adolescents from middle and working class 
backgrounds. In this paper we consider how the theory might help us to understand a persistent failing of the out-of-home care system in the UK, the massive gap in educational achievement between children and youth in public care compared with the general population, and in particular their under-representation in postcompulsory education (Jackson \& Cameron, 2014; Driscoll, 2013).

One of the main tenets of focal theory is that, whilst young people go through many changes during adolescence and early adulthood, they tend to focus on each of these changes in succession, addressing each new challenge as it occurs rather than attempting to contend with them all simultaneously. Thus they are able to avoid, or at least ameliorate, a time of 'storm and stress', as first described by Hall (1904) in his seminal work on adolescence. The few empirical studies that have been conducted to test focal theory have all used 'normative' samples of young people (Simmons et al. 1987; Kroger, 1985; Kloep, 1999; Hendry \& Kloep, 2012).

\section{Coping with life transitions in adolescence}

In his original research, Coleman (1974) interviewed 800 young people aged 11 to 17 about issues in their lives that they identified as stressful. He found that each issue assumed a different level of importance for the young person and reached a peak at a different age. For example, worries about relationships with peers and personal appearance presented earlier than concerns relating to choice of career. Coleman also noted that this pattern did not exclude overlapping, and it was not essential that one issue was resolved before the young person faced the next.

A US based study by Simmons et al (1987) examined the impact in adolescence of experiencing several major life transitions simultaneously. The authors 
hypothesised, on the basis of focal theory, that the stress inherent in these transitions would be reduced if they occurred at different stages and could be tackled individually. The researchers found that those who experienced a number of life changes over a short time were at greater risk in terms of the outcome variables of educational attainment, self-esteem and extracurricular participation. Based on these findings, they emphasise the importance of timing and pacing of transitions and recommend 'gradual rather than discontinuous change, changes that are spread out and dealt with in turn, rather than simultaneously' (p1232). Other US studies also find that care leavers are forced into independent adulthood much earlier than their peers and often have to cope with a multiplicity of life changes at the same time. Typically they face the transition into adult roles with greater challenges and fewer resources than others of the same age (Collins, 2001). Poor outcomes for youth leaving care are reported in all countries: lack of qualifications, unemployment, poverty, substance misuse, early parenthood and homelessness (Stein \& Munro, 2008; Mendes et al, 2011; 2014).

Among 603 young adults in a large-scale study in the US Midwest, 13.8 per cent had been homeless at least once in the year after leaving care (Courtney and Dworsky, 2006). The young people found it particularly hard to manage when a number of difficulties coincided, and since they mostly lacked family support or other forms of social capital, this had a very detrimental effect on their transition to independence, (Courtney \& Heuring, 2005; Keller, Cusick \& Courtney, 2007).

\section{Focal theory in the context of out-of-home care}


The main tenets of focal theory are supported by research with normative samples of adolescents, but there is a dearth of empirical research into its application with nonnormative populations such as young people in and leaving care, whose transitions are likely to be particularly problematic. A few commentators have considered how focal theory might apply to care leavers (Stein, 2006; 2008; Coleman \& Hagell, 2007). Dima and Skehill's (2011) study of care leavers in Romania found further evidence of what Stein has called 'compressed and accelerated transitions' out of care (Stein 2008, 2012). In line with focal theory, they argue that that 'the timing, synchronicity and number of changes make the transition from care to independent living critical for the individual's coping ability' (p.2537).

\section{Data sources}

We go on to consider how focal theory may help us understand the educational experiences of care leavers by revisiting two studies which tracked the educational pathways of care-experienced adolescents and young adults. We look specifically at the notion that young people tend to focus on changes during adolescence one at a time and that there are negative consequences for those who have to cope with multiple, simultaneous transitions. It will also consider to what extent the presence of resources, attributes and 'arenas of comfort' act as protective factors during the process of moving on from care.

We draw on qualitative interview data from two research studies that looked at the post-compulsory education of care leavers in the UK. The first, known as 'By Degrees', was a study of university students with a background in public care (Jackson, Ajayi \& Quigley 2005, 2003: Jackson, 2007). The participants consisted of 
three successive cohorts of care leavers between 2001 and 2006 who had received firm offers of places to study at degree level in UK higher education institutions (HEIs). The first cohort was followed throughout their three year degree courses, the second cohort for two years and the third cohort for their first year. The young people were interviewed on several occasions over the course of the research and took part in a number of focus groups and other events. The final research sample consisted of 150 young people in 68 different HEls, mostly universities (Jackson, 2007; Jackson \& Cameron, 2012).

The second study is 'Young People in Public Care: Pathways to Education in Europe' (YiPPEE) (Cameron, et al, 2011; Jackson \& Cameron, 2012; Jackson \& Cameron, 2014; Jackson \& Höjer, 2014). This was a cross-national project, supported by the European Union, investigating the post-compulsory educational experience of young men and women who had been in public care as children. The research was carried out between 2008 and 2011 by a partnership of five EU countries: England, Denmark, Sweden, Hungary and Spain. The criteria for inclusion were similar to those for By Degrees, that is the young person had to have been in care at the age of 16 and to have spent at least one year in care before that. In practice, the majority of participants had entered care at a young age and remained for many years. Biographical narrative interviews were conducted with between 30 and 35 young people from each country who were then followed up one year later (170 in total). This article draws mainly on data from the 32 participants in the England study (Hauari with Cameron, 2014), but the findings from other countries were similar despite differences in welfare regimes and administrative structures (Jackson \& Cameron, 2014; Montserrat et al, 2013; Racz \& Korintus, 2013). The 
majority of those interviewed were aged between 18 and 21 years; the oldest participant was 25 and the youngest 17.

In the YiPPEE study and in all three By Degrees cohorts women outnumbered men and this was true across all ethnic categories. Approximately half of the participants of both studies were white British, between 20 and 30 per cent were Black or Black British, three to nine per cent were Asian or Asian British, five per cent were Mixed and around ten per cent were of 'Other' ethnic origin. In the By Degrees study there were twice as many females as men in the first cohort, three times as many in the second and the third cohort was 70 per cent female. This is typical of studies relying on volunteers, but also reflects the better performance of girls from disadvantaged backgrounds compared with boys, both in the care and non-care populations. A third factor is that more girls than boys are in foster care, and foster care is more likely than institutional care to offer an environment conducive to educational success (Cameron et al., 2015). The YiPPEE and By Degrees care leavers represented a cross-section of young people in care but both studies were deliberately focused on young people who showed 'educational promise' because one of the objectives was to see how far the care system facilitated or obstructed educational progress.

\section{Findings}

It is [precisely] among those who, for whatever reason, [do] have more than one issue to cope with at a time that problems are most likely to occur" (Coleman \& Hendry, 1999: pp.150) 
The proposition that young people tend to focus on changes and transitions during adolescence 'one at a time' is a principal tenet of focal theory, but evidence from these two studies suggests that this notion is anomalous when applied to the lives of young people who have a care background. The extensive international literature on young people in and leaving care has documented the manifold disadvantages and difficult life events faced by the vast majority, both before their entry to care, during their time in the care system and particularly at the point when they are expected to move to independent living (Stein \& Munro, 2008; Stein, 2012; Mendes et al, 2014). The experiences of those who took part in both the YiPPEE and By Degrees studies are consistent with this finding. Approximately two-thirds of respondents from both studies had been severely abused or neglected. This agrees with national figures in the UK (Department for Education, 2015) which consistently record abuse and/or neglect as the principal reason for reception into care in 60 per cent of cases. Other reasons include death of one or both parents, parental mental illness, substance addiction, family breakdown or coming to the UK as an unaccompanied asylum seeker (30\% of the YiPPEE sample and 16\% from By Degrees). Before entering care, almost all participants had experienced frequently changing family composition and recurrent crises in family life, resulting in childhoods characterised by instability and upheaval with predictably negative effects, particularly in relation to education, for example by making it difficult to concentrate on schoolwork and leading to significant periods out of school altogether:

"I had problems and I went into care and so my education obviously stopped, I was missing for a long time before I went into care, a good 6 months, maybe 8 months... so education wasn't even a factor then... I had problems that were 
more important, like medical problems from being homeless and stuff like that". [YiPPEE participant]

For these young people, the 'voluntaristic positioning' of focal theory, where adolescents exert their agency to manage life transitions and difficulties, is usually not a realistic possibility, supporting Kloep's critique of the theory, at least when applied to atypical groups (Kloep 1999).

The proposition associated with focal theory that having to deal with multiple, simultaneous transitions leads to negative consequences for adolescents (Simmons et al,1987) seems to resonate in much of the research literature and national statistics on young people in and leaving care. These negative outcomes are particularly stark in relation to education as UK statistics illustrate. In $201412.0 \%$ of 'looked after' children (the official term for those in public care) achieved 5 or more GCSEs at grades $A-{ }^{*} \mathrm{C}$, including English and mathematics, compared to $52.1 \%$ of all school children (Department for Education, 2014) and only 6 per cent of care leavers were in higher education at age 19 in 2013 compared to approximately 30\% of young people nationally (Centre for Social Justice, 2014).

Even amongst the care leavers from the YiPPEE and By Degrees studies, who were relatively successful academically, a straightforward progression through education was extremely rare (Jackson \& Cameron, 2012, 2014). Most had experienced instability, unpredictability and interruptions in their educational pathways brought about by moving in and out of care, placement breakdown, neglect and ill-treatment, for example, 50 percent of care leavers in both studies reported having four or more placements. Of the 32 care leavers in the YiPPEE England sample, 14 reported being absent from school for at least one period of 
three months or more, six reported spending 12 months or more out of school, ten young people had moved schools at least once and three reported attending three or more different schools:

"... that really disrupted me. Cos all the times that I was moving was in either October or November ...or it was a time where I was just settled. I think I had to move secondary school twice in my first year". [YiPPEE participant]

Repeated placement moves made it hard to form stable relationships with carers and friends. Social workers often changed jobs and failed to pass on important information about schooling. According to our informants, they did little to avoid changes of school, which often had a devastating effect on the young person's progress. With rare exceptions, there was not enough support or encouragement for educational performance from carers, social workers or teachers to make up for the disadvantage and disruption the young people had experienced throughout childhood (Jackson 2013). The pre-care and in-care lives of the YiPPEE and By Degrees cohorts were typical of the wider care population, marked by co-occurring difficulties and discontinuities not generally experienced by those living with their own families.

The 'compressed and accelerated transitions' experienced on leaving care (Stein, 2002 p.68) further exacerbated the difficulties already faced by these young people. The truncated process of leaving care and the pressure to make the move to independence much earlier than would be expected for others of their age means that care leavers have to face several major life changes without the support and safety net that is usually available to their non-care peers (Höjer and Sjöblom, 2014). The young people from the YiPPEE and By Degrees studies were confronted with 
moving to independent living, learning how to budget, finding employment, beginning courses of further or higher education, managing relationships with family members or partners, all within a very short space of time. Many also had significant caring responsibilities or were young parents. Some, in addition, had to cope with the uncertainties of migrant status. Another transition, for the significant number with health problems (approximately $30 \%$ of participants in the two studies), was moving from child to adult status, which often resulted in a loss of access to services.

There were many examples from both studies of young people being impelled into independent living before they were ready, rushed into decisions which they later regretted but had no chance to reconsider, such as where to live or which educational course to choose:

"I moved out when I was seventeen, and I had too much on my plate. I thought I could cope with it but I couldn't, I couldn't cope with living away from [foster] home, and not having the support that you have when you live at home. It felt lonely where I lived". [By Degrees participant]

Many young people felt they had needed more time and space to prepare for these changes, to try things out, to change direction and to be supported through this process in the way that their family-based peers would be:

"People leaving care need that little bit of extra help you would get from parents especially about managing financially. A lot of the other students used to ring their parents when they needed help but I didn't feel I could. You need someone whose job it is to point you in the right direction". [By Degrees participant] 


\section{The impact on educational pathways}

The By Degrees participants were all at the point of entering tertiary education when they were recruited to the research study, so in that respect this cohort had been much more successful than their peers in overcoming the disadvantages and upheaval of their childhood and care lives. Nevertheless, most faced multiple difficulties which put them at high risk of dropping out. For example, almost one in four of the By Degrees Cohort One young people left their HE course prematurely (Jackson et al 2003). The YiPPEE participants, by definition, had managed to progress into some form of post-compulsory education; however, a quarter of the sample reported failing to complete a course on which they were enrolled.

There were numerous sources of stress for these young people. Financial concerns were widespread, such as struggling to meet the costs of rent or transport when they were not fully covered by the Local Authority. The fear of unmanageable debt hung like a cloud over most of the young people, and prevented them from engaging fully in student life. If they took time out it could be a terrible struggle to reenter education. Care leavers usually found it necessary to work in paid employment alongside their studies in order to manage financially, but this often caused a high level of stress which affected both their academic work and personal life. Other key causes of anxiety were relationship problems, particularly with the birth family and difficulty in coping with a more advanced level of study requiring greater independence in learning.

Many young people struggled to live independently, especially those who were at university but had not been able to secure accommodation in student halls of residence. This often led to feelings of isolation and a lack of emotional support. 
Some reported living a long distance from their educational institution, either by necessity or because of feeling that they could not manage without support from nearby carers, family or friends. Others had left it too late to apply for residence in halls while waiting for confirmation of local authority funding. This often caused problems for young people because of the time and cost of travel to and from classes and the unreliability of public transport. It also prevented them from engaging in 'normal' student activities, as summed up by one young man who left his university course suffering from depression:

"It was very hard, an uphill struggle. Because I was living in a flat quite far out of the city I wasn't part of the university social life. It was just work and study and coming home in the evening to domestic work". [By Degrees participant]

It was when several of these difficulties coincided that young people ran the highest risk of dropping out of their studies. The By Degrees research found that students were most vulnerable to leaving their course prematurely when they experienced three or more stress factors simultaneously (Jackson et al 2003).

There is ample evidence from these two studies to support the focal theory proposition that multiple, simultaneous changes lead to negative consequences for care leavers at a broad level, but at the individual level the picture is more complex. It is easy to underestimate the resilience and achievements of many of those with a care background. Evidence from the YiPPEE and By Degrees studies demonstrates that a significant number successfully navigated their way through numerous difficulties and challenges to complete their courses. But what made this possible? Simmons et al (1987) cited earlier, state that discontinuities and difficult transitions in life are easier to deal with if the person has resources, attributes and, what they 
termed "arenas of comfort" in which they can find sanctuary. This was very evident in the narratives of care leavers from both studies.

Amongst the By Degrees and YiPPEE cohorts there were many participants who were characterised by a strong internal locus of control. It was common for respondents to assert that they could achieve their ambitions if they only worked hard enough. Their desire to secure a stable and happy future for themselves, and to create a family very different from the one they had come from, was a great source of motivation in the face of multiple adversities. Many studies have shown that a strong internal locus of control offers some protection in troubled times (Benzies \& Mychasiuk, 2009; Ross \& Mirowsky, 2013), and this may be particularly true of young people in care (Jackson and Martin 1998).

Even amongst those who went on to complete their education successfully there were times they had felt overwhelmed and considered dropping out, but had managed to persevere and overcome their problems. In most cases this was due to the presence of sources of help and support or 'arenas of comfort'. Having a supportive, long-term, stable foster placement was critical for many young people who had overcome personal issues and had made relatively successful transitions to independence and further or higher education (Jackson 2007; Jackson and Ajayi, 2007). Foster carers who provided consistent support and encouragement, who emphasised the importance of education and advocated for the young person were very important:

"Yes, she [foster carer] got me a home tutor and helped me turn my life around. I suppose if I didn't have her I probably wouldn't be at college. She trusted me, she had faith in me that I could do it. Anything I wanted help with, 
support and stuff at school and that, she was there for me". [YiPPEE participant]

The By Degrees research found that the care leavers with the fewest problems and who made the most successful transitions were those who had a supportive final foster placement which continued to provide an ongoing secure base after they moved to university or independent living (Jackson and Ajayi, 2007; Bentley, 2013; Cameron et al. 2015). Continuing assistance, emotional, practical and in some case financial, from foster carers during and after this transition was a key protective factor, helping to ameliorate the young person's feelings of isolation and loneliness. Knowing they had this ongoing support and 'arena of comfort' to fall back on, similar to the parental support afforded to their non-care peers, made the process more manageable:

"They [foster carers] are proud that I've come to university. They will come and pick me up with all my things at the end of term". [By Degrees participant]

\section{Support from local authorities}

All UK local authorities recognise a duty towards children and youth in out-of-home care in their capacity as 'corporate parents' (Jackson \& Sachdev, 2001). However, the support offered by local authority leaving care teams to young people moving from care to independence in these two studies was variable in type and adequacy, and in many cases was primarily in the form of basic financial or practical help. There were some notable exceptions. For example, in the YiPPEE study, one local authority appointed a dedicated teacher to work full- time as part of the Leaving Care Team. Before his appointment, education had rarely entered team discussions, with 
the main concern being accommodation and employment. This teacher's objective was for all young people known to the team to engage in some form of further education, and in all suitable cases to aim for university. Within five years the number of care leavers from this authority going to university had risen from one to 18 (Jackson and Cameron, 2014). The teacher not only provided educational encouragement and advice but also a high level of practical and emotional support that was much appreciated by the young people:

"He's brilliant, you know, he's the one who you know, goes through all the UCAS [college entrance] stuff with you, he drives people all around the country, he's even got on a plane and gone over to Ireland with somebody to have their college interview. If people have got trouble at college or uni, he's the one who's always there you know, to stick up for you". [YiPPEE participant]

Although, when interviewed, this teacher did not explicitly refer to focal theory, it was clear that he encouraged the young people to create calm spaces in their lives, for example by staying in care as long as possible and not taking on the tenancy of an apartment at the same time as starting a course of further education. There were other examples where particularly committed leaving care workers had been an important resource for young people making key transitions to education or independent living. Sadly, not all young people were so fortunate and a lack of emotional support and care was a key issue that emerged from the interviews with young people from these two studies as it does from other research (Samuels and Pryce, 2008; Höjer and Sjöblom, 2014). 
Some of the By Degrees and YiPPEE care leavers had felt entirely unsupported by their local authority through their transition to independence and in many cases this had a direct impact on whether they had managed to sustain their studies:

"I had no clue and I didn't know how to get into contact with them ever, so I would never know who to ask for help. They started off by making a verbal agreement that they would be in touch once a month and it wasn't. It wasn't even once every six months. It was just like, well, never". [By Degrees participant]

Another young person said:

"It was quite hard because the flat was really, really bad and nothing was working, and the council's attitude was just 'here's the keys, here's some vouchers for decoration, now beat it”. [By Degrees participant]

Suddenly becoming a householder, with all the time-consuming responsibilities that involves, is not at all compatible with concentrated study. However, the alternative could be worse. One young man spoke of the devastating effect of being moved to so-called 'supported lodgings' on his 18th birthday when he was in the middle of important examinations:

“You're just in a room in someone's house, and I found that absolutely daunting, sickening, horrible. l'd only just settled in [Foster home] and she [foster carer] was absolutely fantastic and we was a family. I really, really took things hard when I had to leave, like they ripped away the only person that cared". [YiPPEE participant]

Partly in response to this research, measures have now been put in place in England to enable care leavers to stay in their foster family up to the age of 21 if they and 
their carers wish it (Children \& Families Act, 2014). This does not apply to those living in children's residential homes, which is clearly anomalous, and a hotly disputed issue at the time of writing.

\section{Discussion}

For the majority of care leavers, the contention that young people tend to focus on one transition or change at a time does not resonate with their experience, which is often characterised by disruptions and uncertainty, making it very hard for them to plan ahead. Frequently key decisions about their lives are made by others, at short notice, with little consultation. They are seldom in a position to pace their transitions in the way that focal theory would suggest is desirable.

Evidence from the By Degrees and YiPPEE studies of care leavers who have been educationally and personally successful shows that some resilient individuals are able to make positive transitions to adulthood despite having to face multiple challenges. The five-year follow-up of By Degrees found that the majority of participants had successfully completed their degree or other post-compulsory educational courses and that these people had a much better quality of adult life than the average care leaver, especially the great majority with no educational qualifications (Jackson et al, 2005; Jackson, 2007; Jackson \& Martin, 1998). However, life course outcomes for the majority of adolescents leaving the care system in the UK continue to be poor, and little progress has been made towards narrowing the gap in attainment between care-experienced young people and others. Ongoing research by the present authors has found that there is now more awareness among social workers and other professionals that obtaining educational 
qualifications is crucial to social and labour force integration in adulthood but the difficulty is to turn this perception into effective action (Jackson 2015).

\section{The need for further research}

Secondary analysis of qualitative data from these two studies generally supports the contention of Focal Theory that having to negotiate several transitions in adolescence within a short space of time is likely to lead to less favourable outcomes (Cameron, Connelly \& Jackson, 2015). Although there were individual exceptions, the majority of participants lacked the opportunity to control the timing of important transitions in their lives and often felt bombarded by having to make major decisions at short notice, with an acute lack of support and advice. However, there are limitations to the conclusions that can be drawn from this retrospective analysis in that neither study was originally designed to test Focal Theory. There appear to be no recent studies which make that an explicit aim. Moreover neither By Degrees nor YiPPEE attempted to be representative of the whole care population: both recruited purposive samples from those who had achieved a modest degree of educational success and therefore excluded those most likely to have severe problems on leaving care.

What is needed, therefore, is a prospective study which tracks a random sample of adolescents in out-of-home care through their progress from care to independent adulthood, paying particular attention to the phasing of significant changes and their influence on participation in education and employment. Do young people with a care background attempt to sequence transitions and focus on one at a time like 
other young people? How far do they succeed? Or are their efforts thwarted by the decisions of professionals and administrators over which they have little control?

\section{Implications for policy and practice}

Despite the shortage of robust empirical evidence, there is a prima facie case for incorporating focal theory into work with adolescents making the transition from care to adulthood (Stein, 2008). Both the studies discussed above suggest that this is particularly critical for educational progression. The complex and difficult transitions faced by young people with a care background, especially if they come in quick succession, often have a fatal impact on their learning and educational aspirations as well as their ability to cope with other challenging aspects of their lives.

A first step would be to give young people much more freedom to plan their own pathways, to express their views and be listened to so that they can make changes

when they feel ready rather than on some arbitrary date such as their $18^{\text {th }}$ birthday. The UK has made progress in that direction, and has recognised in a recently published government policy paper that care leavers may need support up to the age of 25 (Department for Education, 2016). There is now provision, for those who wish, to continue in foster family placements up to 21 . This should offer more scope for their carers and statutory advisers to apply the principles of focal theory. However, for that to happen, those principles would need to be better known.

Unlike most proposals for improvement in services, this would not require substantial investment. Raising awareness could be achieved in a half day workshop at a local level, using a case study approach and followed up by supervision and online resources. It is not so much a question of changing practice 
but of enabling practitioners to recognise the theoretical basis for what they may be doing already and giving them an additional argument to deploy in policy discussions or individual cases where they might disagree with their managers. Children in Care Councils (local bodies representing young people in care) should also be involved and would probably have much to contribute (Parker and Gorman, 2013).

Professionals and carers should work together much more effectively to ensure that, wherever possible, young people do not have to face several major changes in a short space of time or at crucial points in their educational careers. There is a need for greater flexibility and a much more gradual transitional period. A better understanding of focal theory could make an important contribution to improved practice in managing transition to adulthood and there is a strong case for incorporating it in training and continuing professional development for all those providing services for young people in out-of-home care: social and youth workers, service managers, teachers, personal advisors and mentors. Most importantly, it is a concept which needs to be understood and internalised by the young people themselves and those providing care.

\section{References}

Bentley, C.I. (2013). Great expectations: Supporting 'unrealistic' aspirations for children in care. In S. Jackson (Ed.) Pathways through education for young people in care: Ideas from research and practice. London: British Association for Adoption and Fostering.

Benzies, K. \& Mychasiuk, R. (2009). Fostering family resilience: A review of the key 
protective factors. Child and Family Social Work, 14, 1, 103-114.

Cameron, C., Connelly, G., \& Jackson, S. (2015). Educating children and young people in care: Learning placements and caring schools. London: Jessica Kingsley.

Cameron, C., Jackson, S., Hauari, H., \& Hollingworth, K. (2011). Young people from a public care background: Pathways to further and higher education in England. $A$ case study. London: Thomas Coram Research Unit.

Centre for Social Justice. (2014). Survival of the fittest? Improving life chances for care leavers. London: Centre for Social Justice.

Children and Families Act 2014. London: The Stationery Office.

Coleman, J. C. (1989). The focal theory of adolescence: A psychological perspective. In K. Hurrelmann \& U. Engel (Eds.), The social world of adolescents: International perspectives. Prevention and intervention in childhood and adolescence (pp. 43-56). Berlin: Walter De Gruyter Inc.

Coleman, J. C. (1978). Current contradictions in adolescent theory. Journal of youth and adolescence, 7, 1-11.

Coleman, J. C. (1974). Relationships in adolescence. London: Routledge.

Coleman, J.C., \& Hagell, A. (2007). Adolescence, Risk and Resilience: Against the odds. Chichester: John Wiley \& Sons Ltd.

Coleman, J.C., \& Hendry, L.B. (1999). The Nature of adolescence. London: 
Routledge.

Collins, M. E. (2001). Transitions to adulthood for vulnerable youths: A review of research and implications for policy. Social Service Review, 75, 2, 271-91.

Courtney, M.E. \& Dworsky, A. (2006). Early outcomes for young adults transitioning from out-of-home care in the USA. Child and Family Social Work, 11, 3, 209219.

Courtney, M.E. \& Heuring, D.H. (2005). The transition to adulthood for youth 'aging out' of the foster care system. In D.W. Osgood., E.M. Foster., C. Flanagan. \& G.R. Ruth (Eds.), On your own without a net: the transition to adulthood for vulnerable populations. Chicago: University of Chicago Press.

Department for Education. (2016). Keep on caring: Supporting young people from care to independence. London: Department for Education.

Department for Education. (2015). Children looked after in England including adoption: 2014 to 2015. London: Department for Education.

Department for Education. (2014). Outcomes for children looked after by local authorities in England as at 31 March 2014. London: Department for Education.

Dima, G., \& Skehill, C. (2011). Making sense of leaving care: The contribution of the Bridges model of transition to understanding the psychosocial process. Children and Youth Services Review, 33, 2532-2539.

Driscoll, J. (2013). Making up lost ground: supporting the education of looked after 
children beyond Key Stage 4. In S. Jackson (Ed.), Pathways through

education for young people in care: Ideas from research and practice (pp.220233). London: British Association for Adoption and Fostering.

Hall, G. S. (1904). Adolescence: its psychology, and its relations to physiology, anthropology, sociology, sex, crime, religion and education. New York: D. Appleton and Co.

Hauari, H. with Cameron, C. (2014). England: A targeted approach. In S. Jackson, \& C. Cameron (Eds.), Improving access to further and higher education for young people in public care (pp. 72-114). London: Jessica Kingsley.

Hendry, L. \& Kloep, M. (2012). Adolescence and Adulthood: Transitions and Transformations. London: Macmillan Education.

Höjer, I., \& Sjöblom, Y. (2014). What Makes a Difference? Turning points for young people in the process of leaving placements in public care. Social Work and Society, $12,1$.

Jackson, S. (2015). The virtual school for children in out-of-home care: A strategic approach to improving their educational attainment. Children Australia, 40, 4, 327334.

Jackson, S. (2013). Introduction to Pathways through education for young people in care: Ideas from research and practice. London: British Association for Adoption \& Fostering. 
Jackson, S. (2007). Care leavers, exclusion and access to higher education. In D. Abrams, J. Christian, \& D. Gordon (Eds.), Multidisciplinary handbook of social exclusion research (pp.115-136). London: Wiley.

Jackson, S., \& Ajayi, S. (2007). Foster care and higher education. Adoption \& Fostering, 31, 1, 106-117.

Jackson, S., Ajayi, S., \& Quigley, M. (2005). Going to university from care. London: Institute of Education.

Jackson, S., Ajayi, S., \& Quigley, M. (2003). By Degrees: The first year. London: National Children's Bureau and the Frank Buttle Trust. Jackson, S., \& Cameron, C. (2014). Improving access to further and higher education for young people in public care. London: Jessica Kingsley. Jackson, S., \& Cameron, C. (2012). Leaving care: Looking ahead and aiming higher. Children and Youth Services Review, 34, 6, 1107-1114. Jackson, S., \& Hojer, I. (2013). Prioritising education for children looked after away from home. European Journal of Social Work, 16, 1, 1-5.

Jackson, S., \& Martin, P.Y. (1998). Surviving the care system: Education and resilience. Journal of Adolescence, 21, 560-583.

Jackson, S. \& Sachdev, D. (2001) Better Education, Better Futures: research, practice and the views of young people in public care. Ifford: Barnardo's.

Keller, T.E., Cusick, G.R. \& Courtney, M.E. (2007) Approaching the transition to 
adulthood: distinctive profiles of adolescents aging out of the child welfare system. Social Services Review, 81, 3, 453-484.

Kloep, M. (1999). Love is all you need? Focusing on adolescents' life concerns from an ecological point of view. Journal of Adolescence, 22, 1, 49-63.

Kroger, J. (1985). Relationships during adolescence: A cross national comparison of New Zealand and United States teenagers. Journal of Youth and Adolescence, 8, $47-56$.

Mendes, P., Johnson, G., \& Moslehuddin, B. (2011). Young people leaving state and out-of-home care: A research-based study of Australian policy and practice. Melbourne: Australian Scholarly.

Mendes, P., Michell, D., \& Wilson, J.Z. (2014). Young people transitioning from outof-home care and higher education: A critical review of the literature. Children Australia, 39, 4, 243-252.

Montserrat, C., Casas, F. \& Malo, S. (2013). Delayed educational pathways and risk of social exclusion: the case of young people from public care in Spain. European Journal of Social Work, 16, 1, 10-21.

Parker, R. \& Gorman, M. (2013) In Care, In School: giving voice to children and young people in care. In S.Jackson (Ed.) Pathways through education for young people in care: Ideas from research and practice (pp.135-145). London: British Association for Adoption \& Fostering. 
Racz, A. \& Korintus, M. (2013). Keeping young people with a care background in education in Hungary: Accommodation with conditions and support. European Journal of Social Work, 16, 1, 55-69.

Ross, C. E. \& Mirowsky, J. (2012). The sense of personal control: Social structural causes and emotional consequences. In C. S. Anshensel, J. C. Phelan \& A. Bierman (Eds.) Handbook of the Sociology of Mental Health (pp.379-402). Netherlands: Springer.

Samuels, G. M., \& Pryce, J. M. (2008). What doesn't kill you makes you stronger: Survivalist self-reliance as resilience and risk among young adults aging out of foster care. Children and Youth Services Review, 30, 10, 1198-1210.

Simmons, R.G., Burgeson, R., Carlton Ford, S., \& Blyth, D.A. (1987). The impact of cumulative change in early adolescence. Child Development, 58, 5, 1220-1234.

Stein, M. (2012). Young people leaving care: Supporting pathways to adulthood. London: Jessica Kingsley.

Stein, M. (2008). Resilience and young people leaving care. Child Care in Practice, $14,1,35-44$

Stein, M. (2006). Young people aging out of care: The poverty of theory. Children and Youth Services Review, 28, 4, 422-434.

Stein, M. (2002). Leaving care. In D. McNeish, T. Newman, \& H. Roberts (Eds.), What works for children? (pp.59-82). Milton Keynes: Open University Press. 
Stein, M. \& Munro, E. R. (2008). Young People's Transitions from Care to Adulthood: International Research and Practice. London: Jessica Kingsley. 